\title{
Telomeric aging: mitotic clock or stress indicator?
}

\author{
Alexander K. Koliada, Dmitry S. Krasnenkov and Alexander M. Vaiserman * \\ D.F. Chebotarev Institute of Gerontology, National Academy of Medical Sciences of Ukraine, Kiev, Ukraine
}

Keywords: age-dependent telomere shortening, telomerase, replicative senescence, oxidative stress

Telomeres are regions of tandem arrays of TTAGGG repeats and associated proteins located at chromosomal ends that allow cells to distinguish chromosome ends from double-strand breaks and protect chromosomes from end-to-end fusion, recombination, and degradation (Houben et al., 2008). Telomeres are not linear structures, telomeric DNA is maintained in a loop structure due to many key proteins. This structure serves to protect the ends of chromosomes (Neidle and Parkinson, 2003). Telomeres are subjected to shortening at each cycle of cell division due to incomplete synthesis of the lagging strand during DNA replication owing to the inability of DNA polymerase to completely replicate the ends of chromosome DNA ("end-replication problem") (Muraki et al., 2012). Therefore, they assume to limit the number of cell cycles and act as a "mitotic clock" (Olovnikov, 1996). Shortened telomeres cause decreased proliferative potential, thus triggering senescence (Blackburn et al., 2006).

Telomere length (TL) is highly heterogeneous in somatic cells, but generally decreases with age in proliferating tissues thereby constituting a barrier to tumorigenesis but also contributing

OPEN ACCESS

Edited by:

Elena G. Pasyukova Institute of Molecular Genetics of Russian Academy of Sciences,

Russia

Reviewed by:

Dominick Burton

Weizmann Institute of Science, Israe Mikhail Vyssokikh,

Moscow State University, Russia

*Correspondence: Alexander M. Vaiserman, vaiserman@geront.kiev.ua

Specialty section: This article was submitted to Genetics of Aging, a section of the journal Frontiers in Genetics

Received: 14 January 2015 Accepted: 16 February 2015 Published: 16 March 2015

Citation: Koliada AK, Krasnenkov DS and Vaiserman AM (2015) Telomeric aging: mitotic clock or stress indicator?

Front. Genet. 6:82.

doi: 10.3389/fgene.2015.00082 to age-related loss of stem cells. Repair of critically short ("uncapped") telomeres by telomerase enzyme, which elongates chromosomal ends by synthesizing new telomeric repeats, is limited in somatic cells, and cellular senescence, apoptosis and/or a permanent cell cycle arrest in G1 phase are triggered by a critical accumulation of uncapped telomeres (D'Souza et al., 2013). Telomerase maintains TL by adding telomeric DNA repeats to chromosome ends in prenatal tissues, gametes, stem cells, and cancerous cells. In proliferative somatic cells, it is usually inactive or expressed at levels that are not high enough to maintain the stable TL (Hiyama and Hiyama, 2007). Alternative lengthening of telomeres (ALT) pathway is a recombination-mediated process, which can increase telomere length by thousands of base-pairs within a few somatic cell cycles (Liu et al., 2007). Telomere-initiated cellular senescence is a mechanism of eliminating cells with damaged DNA and protection against cancerogenesis (through the activation mechanisms of cell cycle arrest or double-strand breaks-induced apoptosis), but it may also impair the cell function contributing to degenerative organ failure and organismal aging (Chen et al., 2007; Campisi, 2013). Cellular senescence (a state of irreversible cell cycle arrest) occurring in response to a telomere shortening may be regulated by immune surveillance. In this process, senescent cells interact with their environment by secreting various growth factors and cytokines, being thereby recognized and eliminated by an antigen-specific immune response (Hoenicke and Zender, 2012; Sagiv and Krizhanovsky, 2013). Shortened telomeres have also been observed in a variety of chronic degenerative diseases, including type 2 diabetes, cardiovascular disease, osteoporosis, and cancer (Armanios, 2013; Babizhayev et al., 2014). The specific molecular mechanism by which short telomeres trigger the development of diseases is, however, not yet determined. It has been proposed that telomere shortening perse might not be a direct signal for cell cycle arrest, but rather the consequence of telomere loss (Vaziri and Benchimol, 1996). It can promote a pro-inflammatory secretory phenotype, in turn contributing to a variety of age-related diseases.

Replicative attrition, however, is not the only explanation for age-dependent telomere shortening. Some studies demonstrate that this process can be non-replicative and significantly stressdependent because of the deficiency of a telomere-specific damage repair (von Zglinicki, 2003). 
Potential stochastic nature of progressive telomere shortening was shown by Levy et al. (1992). Accumulating research findings suggest that psychophysiological stress may accelerate the telomere attrition from early development, and maybe even prenatally, with potential impact for life-long health (Shalev et al., 2013a; Monaghan, 2014). For example, it has been shown that the more violence children had experienced the shorter were their telomeres from 5 to 10 years of age (Shalev et al., 2013b). In the study by Entringer et al. (2011), young adults whose mothers were exposed to severe stressors during pregnancy (for example, due to the death of a close family member) had more short telomeres than those subjects whose mothers had a relatively stress-free pregnancy. Several studies also indicate that effects of exposure to stress early in life may persist into adulthood. In research by Surtees et al. (2011), it has been demonstrated that the more adversity women had experienced during their childhood the shorter were their telomeres in adult life. By investigating the hypothesis that psychophysiological stress may impact health by modulating the rate of cellular aging, Epel et al. (2004) examined the TLs and telomerase activity levels in mothers of healthy or chronically sick children. The second group was predicted to be more chronically stressed than the first one. In this research, mothers of ill children demonstrated substantially reduced telomerase activity which was equivalent to the 9-17 years of additional cellular aging as compared to those women who had healthy children, and rates of cellular aging were obviously associated with levels of stress exposure. Substantial telomere attrition was also revealed among caregivers of $\mathrm{AD}$ (Alzheimer's disease) patients. In this occupational group, telomere shortening was clearly associated with symptoms of depression, in comparison to control subjects matched for gender and age (Damjanovic et al., 2007). The correlation between level of perceived stress and TL was clearly confirmed in a recent meta-analysis conducted by Schutte and Malouff (2014).

Oxidative stress is one of the most important stress factors causing telomere shortening (Houben et al., 2008; Zhang et al., 2014). Telomeric DNA is known to be more susceptible to oxidative damage than non-telomeric DNA, owing to the high content of guanine residues and a reduced DNA repair capacity in telomeric regions (Gomes et al., 2010). Triple guanine repeats of telomeric DNA were shown to be particularly prone to oxidative damage, and they may generate oxidatively modified bases such as 8-oxoguanine which is the main substrate for the base excision repair (BER) pathway (Kawanishi and Oikawa, 2004). Wang et al. (2010) demonstrated that oxidative damage of guanine plays an important role in disruption of telomere integrity and presumes that BER pathway is substantially involved in repair of oxidative base lesions in mammalian telomeres. Moreover, telomeric DNA, in contrast to genomic DNA, is deficient in repair of single strand breaks and double strand breaks, and telomere dysfunction is believed to mediate the effect of oxidative base damage to abnormal nuclear morphology (Coluzzi et al., 2014). In human cell lines, telomeres generally shorten by $30-200$ base pairs at each round of DNA replication, but only approximately 10 base pairs of this reduction are a consequence of the end-replication problem; the remaining loss is likely owing to oxidative damage (Monaghan and Haussmann, 2006). Systemic chronic inflammation to accelerate aging via ROS-mediated telomere dysfunction and cell senescence was shown in mice (Jurk et al., 2014).

In several studies, it was found, that DNA damaging agents cause telomere erosion, primarily, by high levels of reactive oxygen species (ROS) regardless of age of the cell donor. For example, in the Richter and von Zglinicki (2007) study, high levels of oxidative stress cause accelerated rates of telomere erosion and, ultimately, arrest of the cell cycle in cell cultures derived from donors of various ages (embryonic to adult). Moreover, it was revealed that over-expression of superoxide dismutase in a cell line with low antioxidant capacity slowed erosion of telomeres (Serra et al., 2003). Further evidence for non-replicative cause of telomere shortening comes from the fact that the telomere erosion rate varies in a stochastic manner among cells in fibroblast clones, derived from single cells, thereby causing sub-clonal heterogeneity in replicative lifespan (Martin-Ruiz et al., 2004). Recently, it was found that such cell-to-cell heterogeneity may come from stochastic heterogeneity in oxidative DNA damage caused, e.g., by variations in the cell's metabolic processes (Snijder and Pelkmans, 2011; Trusina, 2014). Another pathway for nonreplicative telomere erosion relates to non-canonical function of telomerase, mainly, protection of mitochondria against oxidative stress (Saretzki, 2014). The fact that TERT is transported out of the nucleus under long-term low level oxidative stress suggests that protection of mitochondrial DNA might have higher priority than protection of telomeres maintenance under stress (Ahmed et al., 2008).

The complexity of processes underlying age-related telomere erosion came from several longitudinal studies of telomere dynamics in vivo. Research of TLs in blood cells of snakes, birds, and humans unexpectedly revealed, that no TLs changes with aging were found (for review, see Eisenberg, 2011). Moreover, the faster age-related decline in leukocyte TLs was observed among subjects with longer telomeres at baseline early-adult examinations, suggesting that longer telomeres provide bigger amount of targets for oxidative stress-related telomere erosion (Aviv et al., 2009). Traditionally, it was assumed that telomeres are stable structures, which may be changed only in unidirectional wayshortening over the lifetime. Today, however, it has become increasingly clear that telomeres shortening over time in an oscillatory rather than linear fashion and they may be either shortened or lengthened under certain conditions (Epel, 2012). Several pilot studies indicate that treatment procedures targeting to reduce stress, e.g., meditation, along with the enhanced physical activity and changes in dietary patterns, can slow or even reverse telomere shortening owing to the elevated telomerase activity (Jacobs et al., 2011; Blackburn and Epel, 2012). The elongation of telomeres may be caused by the telomerase-mediated extension or appear due to the "pseudo-telomeric lengthening." The latest is due to the fact that, since TLs are commonly measured in a mixed leukocyte population, mean TL can increase because of a redistribution of cell subpopulations, i.e., change in the percentage of various cell types in the blood samples.

Consistent evidence suggest that telomere erosion may be a common mechanism that triggers all major processes underlying aging, including mutation accumulation, mitochondrial dysfunction and stem cell failure (Armanios, 2013), as well as epigenetic 
changes likely through silencing of gene expression by formation of long-range chromatin interactions (Fojtová and Fajkus, 2014; Misteli, 2014). Induction of senescence occurs in reaction to a critically short telomere length and to the triggering of DNA damage response. Therefore, unraveling the factors causing telomere attrition may be important for further progress in understanding the basic mechanisms of aging. In this context, it is particularly important to establish the relative significance of end-replication and oxidative damage events in the age-related telomere erosion.

Given data from recent studies, a concept that replicative senescence is a "clocked" and stepwise process seems doubtful, and repeatedly reported reproducibility of both replicative lifespans and rates of telomere shortening could be the result of stochastic rather than programmed events (von Zglinicki, 2003). In other words, it seems that telomeres can be an indicator of stress-induced damage level rather than a mitosis "counter."

\section{References}

Ahmed, S., Passos, J. F., Birket, M. J., Beckmann, T., Brings, S., Peters, H., et al. (2008). Telomerase does not counteract telomere shortening but protects mitochondrial function under oxidative stress. J. Cell Sci. 121, 1046-1053. doi: $10.1242 /$ jcs.019372

Armanios, M. (2013). Telomeres and age-related disease: how telomere biology informs clinical paradigms. J. Clin. Invest. 123, 996-1002. doi: 10.1172/JCI66370

Aviv, A., Chen, W., Gardner, J. P., Kimura, M., Brimacombe, M., Cao, X., et al. (2009). Leukocyte telomere dynamics: Longitudinal findings among young adults in the Bogalusa Heart Study. Am. J. Epidemiol. 16, 323-329. doi: 10.1093/aje/kwn338

Babizhayev, M. A., Vishnyakova, K. S., and Yegorov, Y. E. (2014). Oxidative damage impact on aging and age-related diseases: drug targeting of telomere attrition and dynamic telomerase activity flirting with imidazolecontaining dipeptides. Recent Pat. Drug Deliv. Formul. 8, 163-192. doi: 10.2174/1872211308666140602125505

Blackburn, E. H., and Epel, E. S. (2012). Telomeres and adversity: too toxic to ignore. Nature 490, 169-171. doi: 10.1038/490169a

Blackburn, E. H., Greider, C. W., and Szostak, J. W. (2006). Telomeres and telomerase: the path from maize, Tetrahymena and yeast to human cancer and aging. Nat. Med. 12, 1133-1138. doi: 10.1038/nm1006-1133

Campisi, J. (2013). Aging, cellular senescence, and cancer. Annu. Rev. Physiol. 75, 685-705. doi: 10.1146/annurev-physiol-030212-183653

Chen, J. H., Hales, C. N., and Ozanne, S. E. (2007). DNA damage, cellular senescence and organismal ageing: causal or correlative? Nucleic Acids Res. 35, 7417-7428. doi: 10.1093/nar/gkm681

Coluzzi, E., Colamartino, M., Cozzi, R., Leone, S., Meneghini, C., O’Callaghan, N., et al. (2014). Oxidative stress induces persistent telomeric DNA damage responsible for nuclear morphology change in mammalian cells. PLoS ONE 9:e110963. doi: 10.1371/journal.pone.0110963

Damjanovic, A. K., Yang, Y., Glaser, R., Kiecolt-Glaser, J. K., Nguyen, H., Laskowski, B., et al. (2007). Accelerated telomere erosion is associated with a declining immune function of caregivers of Alzheimer's disease patients. $J$ Immunol. 179, 4249-4254. doi: 10.4049/jimmunol.179.6.4249

D'Souza, Y., Lauzon, C., Chu, T. W., and Autexier, C. (2013). Regulation of telomere length and homeostasis by telomerase enzyme processivity. J. Cell Sci. 126, 676-687. doi: $10.1242 /$ jcs.119297

Eisenberg, D. T. (2011). An evolutionary review of human telomere biology: the thrifty telomere hypothesis and notes on potential adaptive paternal effects. Am. J. Hum. Biol. 23, 149-167. doi: 10.1002/ajhb.21127

Entringer, S., Epel, E. S., Kumsta, R., Lin, J., Hellhammer, D. H., Blackburn, E. H., et al. (2011). Stress exposure in intrauterine life is associated with shorter
Moreover, considering the fact that oxidative stress represents a common causative mechanism for both age-related telomere shortening (Houben et al., 2008) and age-associated disease (Richardson and Schadt, 2014), there are reasons to believe that relationships between TL and morbidity or mortality are non-causal, and TL can be an indicator of previous exposure to oxidative stress that may, in turn, cause both greater telomere shortening and higher risk of chronic disease. Thereby, perceived stressful events, though correlated with TL, may likely have independent effects on health and longevity (Eisenberg, 2011). By summarizing recent research findings, Trusina (2014) conclude that recently obtained knowledge "shift the telomere paradigm from a simple clock counting cell divisions to a more complex process recording the history of stress exposure within a cell lineage." This point of view, based on the accumulated evidence, appears plausible, and requires further investigation.

telomere length in young adulthood. Proc. Natl. Acad. Sci. U.S.A. 108, 513-518. doi: $10.1073 /$ pnas. 1107759108

Epel, E. (2012). How "reversible" is telomeric aging? Cancer Prev. Res. (Phila.) 5, 1163-1168. doi: 10.1158/1940-6207.CAPR-12-0370

Epel, E. S., Blackburn, E. H., Lin, J., Dhabhar, F. S., Adler, N. E., Morrow, J. D., et al. (2004). Accelerated telomere shortening in response to life stress. Proc. Natl. Acad Sci. U.S.A. 101, 17312-17315. doi: 10.1073/pnas.0407162101

Fojtová, M., and Fajkus, J. (2014). Epigenetic regulation of telomere maintenance. Cytogenet. Genome Res. 143, 125-135. doi: 10.1159/000360775

Gomes, N. M., Shay, J. W., and Wright, W. E. (2010). "Telomeres and telomerase," in The Comparative Biology of Aging, ed N. S. Wolf (New York, NY: Springer), 227-258.

Hiyama, E., and Hiyama, K. (2007). Telomere and telomerase in stem cells. Br. J. Cancer 96, 1020-1024. doi: 10.1038/sj.bjc.6603671

Hoenicke, L., and Zender, L. (2012). Immune surveillance of senescent cellsbiological significance in cancer- and non-cancer pathologies. Carcinogenesis 33, 1123-1126. doi: 10.1093/carcin/bgs124

Houben, J. M., Moonen, H. J., van Schooten, F. J., and Hageman, G. J. (2008). Telomere length assessment: biomarker of chronic oxidative stress? Free Radic. Biol. Med. 44, 235-246. doi: 10.1016/j.freeradbiomed.2007.10.001

Jacobs, T. L., Epel, E. S., Lin, J., Blackburn, E. H., Wolkowitz, O. M., Bridwell, D. A., et al. (2011). Intensive meditation training, immune cell telomerase activity, and psychological mediators. Psychoneuroendocrinology 36, 664-681. doi: 10.1016/j.psyneuen.2010.09.010

Jurk, D., Wilson, C., Passos, J. F., Oakley, F., Correia-Melo, C., Greaves, L., et al. (2014). Chronic inflammation induces telomere dysfunction and accelerates ageing in mice. Nat. Commun. 2:4172. doi: 10.1038/ncomms5172

Kawanishi, S., and Oikawa, S. (2004). Mechanism of telomere shortening by oxidative stress. Ann. N.Y. Acad. Sci. 1019, 278-284. doi: 10.1196/annals.12 97.047

Levy, M. Z., Allsopp, R. C., Futcher, A. B., Greider, C. W., and Harley, C. B. (1992). Telomere end-replication problem and cell aging. J. Mol. Biol. 225, 951-960. doi: 10.1016/0022-2836(92)90096-3

Liu, L., Bailey, S. M., Okuka, M., Muñoz, P., Li, C., Zhou, L., et al. (2007). Telomere lengthening early in development. Nat. Cell Biol. 9, 1436-1441. doi: $10.1038 /$ ncb1664

Martin-Ruiz, C., Saretzki, G., Petrie, J., Ladhoff, J., Jeyapalan, J., Wei, W., et al. (2004). Stochastic variation in telomere shortening rate causes heterogeneity of human fibroblast replicative lifespan. J. Biol. Chem. 279, 17826-17833. doi: 10.1074/jbc.M311980200

Misteli, T. (2014). The long reach of telomeres. Genes Dev. 28, 2445-2446. doi: $10.1101 /$ gad.254573.114

Monaghan, P., and Haussmann, M. F. (2006). Do telomere dynamics link lifestyle and lifespan? Trends Ecol. Evol. 21, 47-53. doi: 10.1016/j.tree.2005.11.007 
Monaghan, P. (2014). Organismal stress, telomeres and life histories. J. Exp. Biol. 217, 57-66. doi: 10.1242/jeb.090043

Muraki, K., Nyhan, K., Han, L., and Murnane, J. P. (2012). Mechanisms of telomere loss and their consequences for chromosome instability. Front. Oncol. 2:135. doi: 10.3389/fonc.2012.00135

Neidle, S., and Parkinson, G. N. (2003). The structure of telomeric DNA. Curr. Opin. Struct. Biol. 13, 275-283. doi: 10.1016/S0959-440X(03)00072-1

Olovnikov, A. M. (1996). Telomeres, telomerase, and aging: origin of the theory. Exp. Gerontol. 31, 443-448. doi: 10.1016/0531-5565(96)00005-8

Richardson, A. G., and Schadt, E. E. (2014). The role of macromolecular damage in aging and age-related disease. J. Gerontol. A Biol. Sci. Med. Sci. 69, 28-32. doi: 10.1093/gerona/glu056

Richter, T., and von Zglinicki, T. (2007). A continuous correlation between oxidative stress and telomere shortening in fibroblasts. Exp. Gerontol. 42, 1039-1042. doi: 10.1016/j.exger.2007.08.005

Sagiv, A., and Krizhanovsky, V. (2013). Immunosurveillance of senescent cells: the bright side of the senescence program. Biogerontology 14, 617-628. doi: 10.1007/s10522-013-9473-0

Saretzki, G. (2014). Extra-telomeric functions of human telomerase: cancer, mitochondria and oxidative stress. Curr. Pharm. Des. 20, 6386-6403. doi: 10.2174/1381612820666140630095606

Schutte, N. S., and Malouff, J. M. (2014). The relationship between perceived stress and telomere length: a meta-analysis. Stress Health. doi: 10.1002/smi.2607. [Epub ahead of print].

Serra, V., von Zglinicki, T., Lorenz, M., and Saretzki, G. (2003). Extracellular superoxide dismutase is a major antioxidant in human fibroblasts and slows telomere shortening. J. Biol. Chem. 278, 6824-6830. doi: 10.1074/jbc.M2079 39200

Shalev, I., Entringer, S., Wadhwa, P. D., Wolkowitz, O. M., Puterman, E., Lin, J., et al. (2013a). Stress and telomere biology: a lifespan perspective. Psychoneuroendocrinology 38, 1835-1842. doi: 10.1016/j.psyneuen.2013.03.010

Shalev, I., Moffitt, T. E., Sugden, K., Williams, B., Houts, R. M., Danese, A., et al. (2013b). Exposure to violence during childhood is associated with telomere erosion from 5 to 10 years of age: a longitudinal study. Mol. Psychiatry 18, 576-581. doi: $10.1038 / \mathrm{mp} .2012 .32$
Snijder, B., and Pelkmans, L. (2011). Origins of regulated cell-to-cell variability. Nat. Rev. Mol. Cell. Biol. 12, 119-125. doi: 10.1038/nrm3044

Surtees, P. G., Wainwright, N. W., Pooley, K. A., Luben, R. N., Khaw, K. T., Easton, D. F., et al. (2011). Life stress, emotional health, and mean telomere length in the European Prospective Investigation into Cancer (EPIC)Norfolk population study. J. Gerontol. A Biol. Sci. Med. Sci. 66, 1152-1162. doi: 10.1093/gerona/glr112

Trusina, A. (2014). Stress induced telomere shortening: longer life with less mutations? BMC Syst. Biol. 8:27. doi: 10.1186/1752 0509-8-27

Vaziri, H., and Benchimol, S. (1996). From telomere loss to p53 induction and activation of a DNA-damage pathway at senescence: the telomere loss/DNA damage model of cell aging. Exp. Gerontol. 31, 295-301. doi: 10.1016/05315565(95)02025-X

von Zglinicki, T. (2003). Replicative senescence and the art of counting. Exp. Gerontol. 38, 1259-1264. doi: 10.1016/j.exger.2003.09.015

Wang, Z., Rhee, D. B., Lu, J., Bohr, C. T., Zhou, F., Vallabhaneni, H., et al. (2010). Characterization of oxidative guanine damage and repair in mammalian telomeres. PLoS Genet. 6:e1000951. doi: 10.1371/journal.pgen. 1000951

Zhang, L., Hu, X. Z., Li, X., Li, H., Smerin, S., Russell, D., et al. (2014). Telomere length - a cellular aging marker for depression and post-traumatic stress disorder. Med. Hypotheses. 83, 182-185. doi: 10.1016/j.mehy.2014. 04.033

Conflict of Interest Statement: The authors declare that the research was conducted in the absence of any commercial or financial relationships that could be construed as a potential conflict of interest.

Copyright ( $\odot 2015$ Koliada, Krasnenkov and Vaiserman. This is an open-access article distributed under the terms of the Creative Commons Attribution License (CC $B Y)$. The use, distribution or reproduction in other forums is permitted, provided the original author(s) or licensor are credited and that the original publication in this journal is cited, in accordance with accepted academic practice. No use, distribution or reproduction is permitted which does not comply with these terms. 